\title{
Perforating brain injury from a speargun. A case report
}

\author{
J. Abarca-Olivas; L.A. Concepción-Aramendía*; E. Baño-Ruiz; M.A. Caminero-Canas; J.A Navarro-Moncho y C. \\ Botella-Asunción \\ Departmentos de Neurocirugia y Neurorradiología*. Hospital General Universitario de Alicante. Alicante, España.
}

\section{Summary}

A case of a perforating brain injury caused by a speargun in a suicide attempt is described. Although this kind of injuries has been previously reported, the present case is specially interesting because the patient showed no neurological deficit after surgery. Some advices about the medical and surgical management are proposed based on this case and our literature review. The use of antibiotics and antiepileptic drugs and the anterograde extraction of the harpoon aided by the performance of a craniotomy surrounding the exit point are recommended.

KEY WORDS. Speargun. Perforating injury. Cranial trauma.

Traumatismo craneal perforante por arpón de pesca. A propósito de un caso

\section{Resumen}

Describimos un caso de traumatismo craneo-encefálico perforante causado por un arpón de pesca submarina tras intento de autolisis. Aunque traumatismos parecidos han sido publicados previamente, el presente caso es especialmente interesante dada la escasa repercusión neurológica que el paciente presentó tras la cirugia. Basándonos en esta experiencia y en nuestra revisión bibliográfica proponemos algunos consejos que pueden ser de utilidad en el manejo médico y quirúrgico. El uso de antibióticos y antiepilépticos así como la extracción anterógrada del arpón con la ayuda de una craneotomía rodeando su punto de salida son algunas de estas recomendaciones.

PALABRAS CLAVE. Arpón. Traumatismo perforante. Traumatismo craneal.

Recibido: 10-06-10. Aceptado: 3-04-11.

\section{Introduction}

The penetrating or perforating injuries of the skull usually cause serious damage to the parenchyma or neurovascular structures of the brain. Those of middle and anterior location are especially dangerous ${ }^{2,9,10,14,18}$. Most of them are due to the negligence of the security rules established for underwater fishing ${ }^{6}$. Our case is the only one found in the literature due to an attempted suicide. Despite the dangerous trajectory of the arrow, the patient had an excellent neurological outcome after surgical management. Surprisingly, similar cases without neurological deficits have been reported by other authors ${ }^{3,7,8,11,13,15,20}$. However, the establishment of management rules in this kind of injuries is difficult because of the variability of reported cases. Based on our experience and a literature review we have realized that craniofacial injuries caused by spearguns present some particular features that allow us to propose some specific advices.

\section{Case report}

\section{Preoperative managment}

A 34-year-old male shot himself in the head with a speargun in a suicide attempt. He did not lose conciousness and was taken to his local hospital where he arrived alert and didn't show any neurological deficit in a quick neurological evaluation. Before being transferred to our hospital the patient was anesthetized and intubated. The trajectory of the harpoon did not impede the intubation maneuver. On arrival at our Intensive Care Unit the man was sedated and showed stable vital signs. The proximal half of the arrow was cut shorter to mobilize the patient better. This procedure was performed with an cold saw ( sawing machine that uses a circular saw blade to cut metal) with extreme caution to prevent transmission of vibrations trough the brain. The arrow traversed the patient's head (Fig1): the entry point was the submental region and the projectile passed trough the tongue, palatal bone, right ethmoidal bone, medial wall of orbital apex, anterior cranial fossa and finally the fron- 


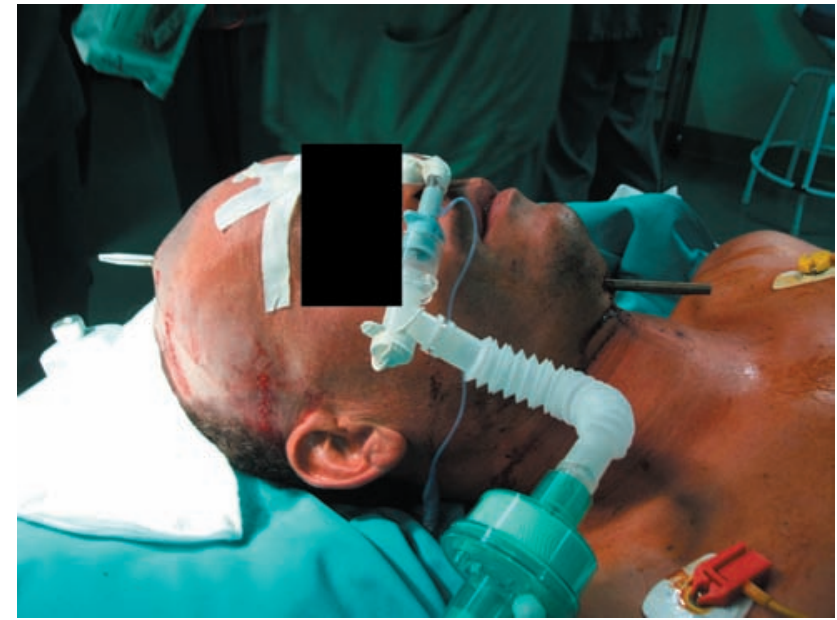

Figure 1. An external view of speargun arrow trajectory is showed. The proximal half of the arrow has been cut shorter to mobilize the patient better. Before being transferred to the our hospital the patient was anesthetized and intubated.

tal lobe before reaching the exit point in the right coronal suture about $4 \mathrm{cms}$ away from the sagital sinus.

The length of the object was approximately $80 \mathrm{~cm}$ long and $8 \mathrm{~mm}$ in diameter. Broad-spectrum antibiotic and an anticonvulsant were administered since its admission in the emergency department. Surprisingly, no hemorrhagic lesions or associated edema was noticed in CT-scan before surgery (Fig 2). The patient is transferred to the operating room for removal of the projectile 2 hours after admision. Before surgery we asked his family for bringing us a similar speargun in order to improve our knowledge about the structure and functioning of the object.

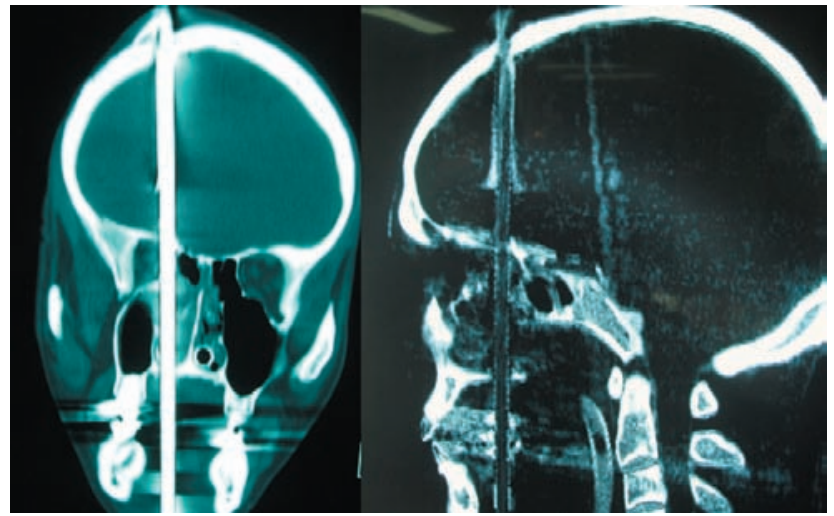

Figure 2. Coronal and sagital sections CT-scan showing the intracranial trajectory of the proyectile. The projectile passed trough the tongue, palatal bone, right ethmoidal bone, medial wall of orbital apex, anterior cranial fossa and finally the frontal lobe before reaching the exit point in the right coronal suture about $4 \mathrm{cms}$ away from the sagital sinus.

\section{Surgical procedure}

The patient was placed in supine decubitus position and his head was shaved and prepared without rotation. Rigid fixation of skull was not used. Meticulous cleaning and debriding of both entry and exit wounds was performed and the arrow was sterilized with antiseptic liquid. We made a vertical incision of $4 \mathrm{~cm}$ taking the exit of the projectile as the midpoint. The bone around the hole was well preserved without comminuted fractures. As the strongest attachment of this kind of objects is the bone, an small craniotomy surrounding the harpoon was performed to make

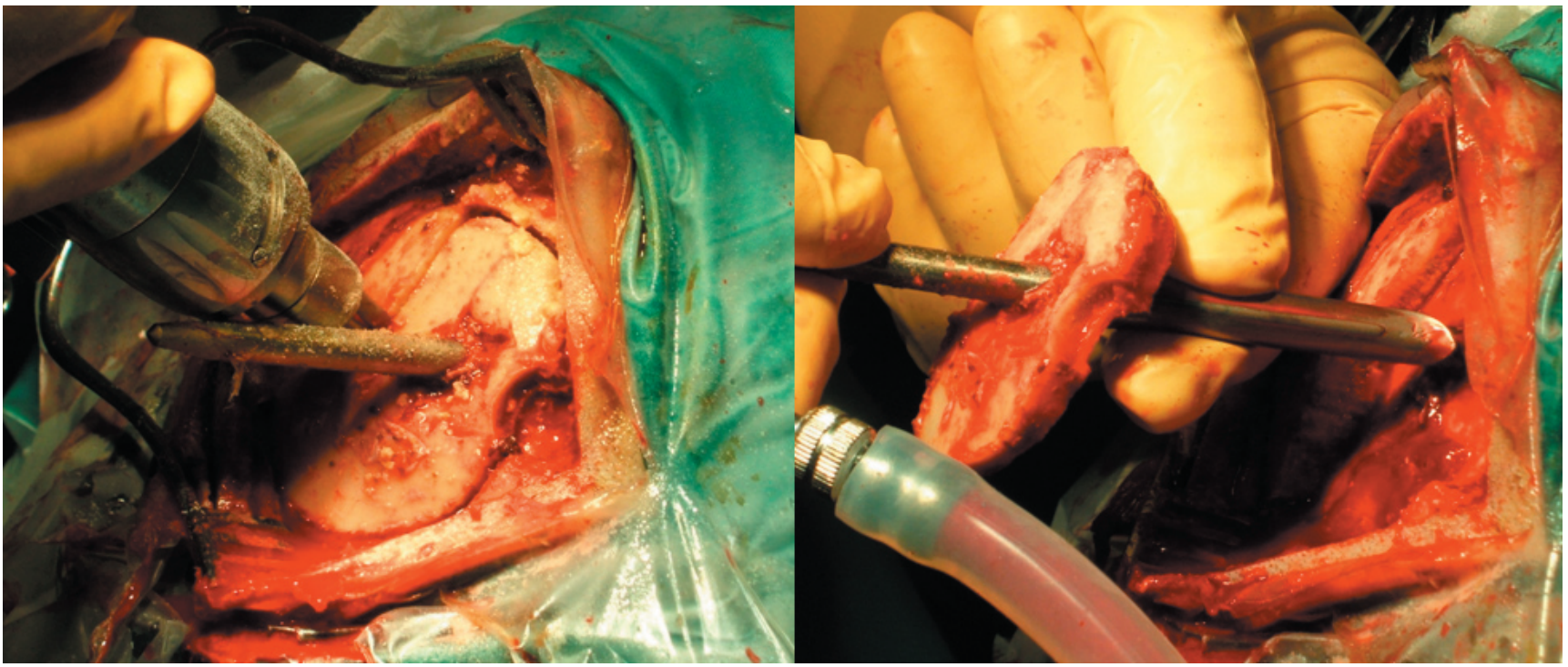

Figure 3. A small craniotomy surrounding the exit hole is performed in order to make the arrow removal easier. Both the bone flap and the projectile were gently removed by pulling them from the coronal region with the aid of rongeurs. 
the extraction easier. This way both the bone flap and the projectile were gently removed by pulling them from the coronal region with the aid of rongeurs along the original trajectory of the missile (Fig3).

After this risky maneuver, the dura was opened to check that no active bleeding flowed from the cerebral cortex. At the same time an otolaryngologist explored the paranasal trayect. No CSF leak was found. After meticulous hemostasis was achieved, dural repair was performed with an artificial substitute. The corticotomy area was irrigated with vancomycin diluted in saline. The bone flap was separated from the arrow and asepticized before being replaced with miniplates.

\section{Postoperative management}

An immediate CTscan was performed and showed minimal amount of pneumoencephalus and blood along the projectile trayectory (Fig4).

The patient was then taken back to the Intensive Care Unit, where he was kept under relaxation and sedation for $24 \mathrm{~h}$ with broad-spectrum antibiotics and anticonvulsivants. Intracranial pressure was monitored remaining below $10 \mathrm{~mm} \mathrm{Hg}$. When sedation was removed and the patient awoke he only suffered diplopia but later this visual problems improved and the patient showed no neurological deficit on 4th day after surgery. The patient did not mention rhinorrhea and a CTscan perfomed 1 week post-op demonstrated a small hypointense lesion involving the right frontal area. The wounds healed without complications and he had no postoperative seizures. The patient was discharged on 8th day and was transferred to a psychiatric hospital. A few months after the trauma, neuropsychiatric reports certified a significant improvement of depressive mood and suicidal ideation of the patient.

\section{Discussion}

This case is exceptional not only for the type of trauma but because of the absence of neurological sequelae at discharge. Penetrating head injury is more common than perforating which is often associated with increased risk of neurological complications, especially if the trajectory crosses the midline from a lateral entrance of the skull $1,4,7,9,12,14$.

Scientific papers that report cases of head trauma by speargun are insufficient to develop specific recommendations about the surgical procedure. Furthermore, the variability between each accident makes more difficult to establish performance standards in these cases $^{6,8}$. However, some advices can be proposed. First of all it is important to have imaging tests (especially CT-scan ) to provide information about brain injuries caused by the arrow along its

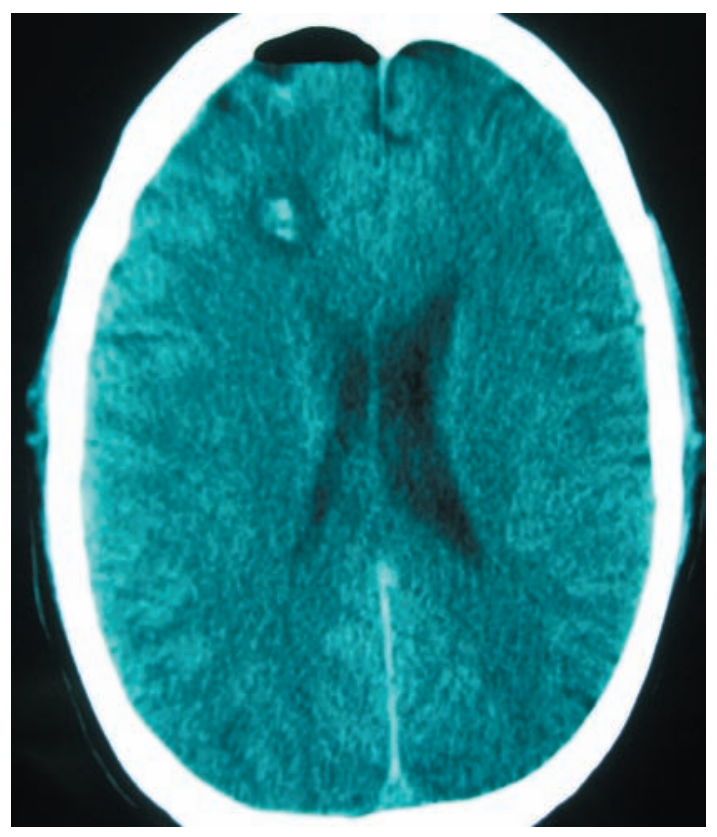

Figure 4. A minimal amount of pneumoencephalus and blood is showed by the inmediate postoperative CT-scan.

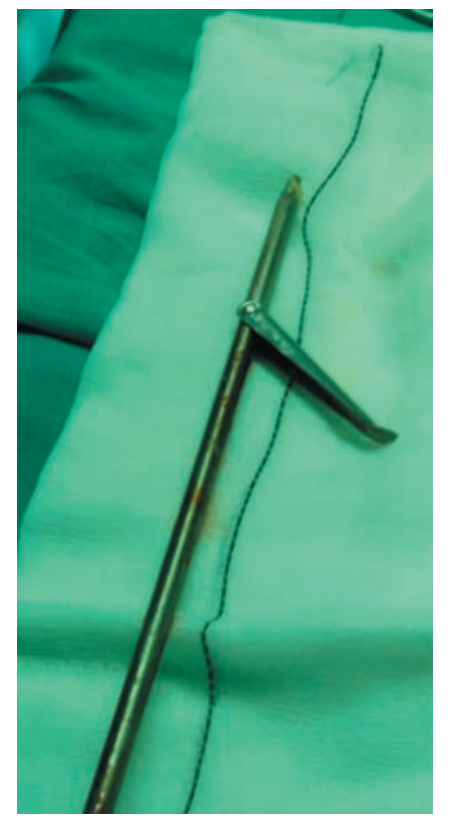

Figure 5. A picture of the speargun arrow after extraction. The projectile was constructed of an iron shaft in whose tip there was a blade capable of opening.

trajectory ${ }^{4,8}$. As in all perforating trauma is very important to have proper control of the entry and exit points. Sometimes the length of the arrow makes the mobilization of the patient difficult. Some authors advise against cutting the arrow to prevent transmission of vibrations to the brain ${ }^{6}$. However in our case this procedure was done with a cold saw, safer than hacksaws used formerly. In our opinion, if 
the maneuver is performed with this tool by a specialist the arrow may be cut safely. Proper planning about the direction of extraction is also crucial. For this purpose it is advisable to have not only imaging tests but adequate information on the characteristics of the object ${ }^{16,19}$. In the present case, the speargun arrow was constructed of an iron shaft in whose tip there was a blade capable of opening, by means of a spring, on contact with the target. Something specific to harpoon removal is that the projectile must be removed in an anterograde fashion, that is in the direction of its line of trajectory, to avoid accidental opening of the weapon's blade (Fig 5), which would cause further cerebral damage.

Extraction should never be attempted until a good control of entry and exit points is assured. In most cases of these cases the area of greater adherence of the harpoon is the skull convexity. For this reason, when the exit point is located in this area, a craniotomy surrounding the hole may help remove the harpoon and the attached bone flap. By contrast, if the entry hole is embedded in the convexity, we propose that this segment of the harpoon should be released from bone before being removed. The use of intraoperative and postoperative antibiotics and a thorough antisepsis of the surgical area as well as the object to extract are strongly recommended. The size of the craniotomy depends on the need to evacuate hematoma during surgery ${ }^{7}$. In our case we decided to make a small craniotomy although the surgical field was ready for expansion if necessary. There are no studies that have compared the use of synthetic or autologous dural or bone substitutes in such patients. In our patient a synthetic substitute was used to fill the dural hole and the original patient's bone was replaced after drilling the area in contact with the harpoon and sterilizing the whole flap with antiseptic solution.

If the missile trajectory suggests the possibility of a vascular injury an angiography must be performed, either before surgical treatment or soon after it, according to the experience gained with penetrating stab wounds to the head $\mathrm{d}^{4,5,13,17,21}$. The trajectory of the projectile in our patient did not suggest vascular damage, therefore an arteriography was not considered necessary. The prophylactic use of antiepileptic drugs is recommended in these patients even in the absence of early crisis due to the high probability of developing epilepsy later ${ }^{1,22}$. Our patient was treated with phenytoin every 8 hours for 6 months after surgery. No seizures were referred by the patient after discharge.

\section{Conclusion}

We present the first reported case of a traumatic brain injury caused by a speargun in a suicide attempt. This case illustrates the difficulties in making decisions in the surgical management of perforating brain injuries caused by unusual objects. The special features of this kind of trauma and the absence of cases reported make necessary to propose some specific rules about surgical removal and medical treatment. The use of antibiotics and antiepileptic drugs and the anterograde extraction of the harpoon aided by the performance of a craniotomy surrounding the exit point are some of the most important advices proposed in these cases.

\section{References}

1. Aarabi, B., Taghipour, M., Haghnegahdar, A., Farokhi, M., Mobley, L.L.: Prognostic factor in the ocurrente of posttraumatic epilepsy after penetrating head injury suffered during military service. Neurosur Focus 2000; 8: article 1.

2. Adeloye, A.: Mortality in missile wound of the head. $\mathrm{Br}$ J. Surg 1985, 59: 89.

3. Ashkenazi, E., Mualem, N., Umanski, F.: Successfull removal of an intracranial needle by an ophthalmologic magnet: a case report. J Trauma 1990; 30: 114-115.

4. De Villiers, J.C.: Stab wounds of the brain and skull. En Vinken PJ, Bruyn GW, eds.: Handbook of Clinical Neurology 1975; Vol. 23. Amsterdam, Elsevier North-Holland pp. 477503.

5. Du Trevou, M.D., van Dellen, J.R.: Penetrating stab wounds to the brain: The timing of angiography in patients presenting with the weapon already removed. Neurosurgery 1992; 31: 905-912.

6. Fernández-Melo, R., Morán, A.F., López-Flores, G., Bouza-Molina, W., García-Maeso, I., Benavides-Barbosas, J.: Penetrating head injury from harpoon. Case report. Neurocirugía 2002; 13: 397-400.

7. Gil, J.J., Acosta, C.: Proceder quirúrgico aplicado a un paciente accidentado con arpón intracraneal. Silac 1995; 3: 28-35.

8. Gil, J.J., Acosta, C., Felipe, A., Alemán, A., Pérez, F., Trigo, G.: Consideraciones y proceder quirúrgico en las heridas craneocerebrales por arpón. Rev Cubana Med Milit 1998; 27: 133-140.

9. Gluncic, I., Roje, Z., Tudor, M., Gluncic, V.: Unusual stab wound of the temporal region. Croat Med J 2001; 42: 579-582.

10. Hammon, W.M.: Analysis of 2187 consecutive penetrating wounds of the brain from Vietnam. J Neurosurg 1975; 34: 127.

11. Hansen, J.E., Godman, S.K.: Penetrating cranial cerebral injuries from a modem air powered nailen A case report. BNI. Quiart 1987; 3: 35-37.

12. Haworth, C.S., de Villiers, J.C.: Stab rounds to the temporal fossa. Neurosurgery 1988: 23: 431-435.

13. Kelly, D.F., Nikas, D.L., Becker, D.P.: Diagnosis and treatment of moderate and severe head injuries in adult. En Youmans, J.R. Neurological Surgery 1996; Philadelphia, WB Saunders pp. 1618-1718. 
14. Khalil, N., Elwany, M.N., Miller, J.D.: Transcranial Stab Wounds: Mortality and Medico Legal Awareness. Surg Neurol 1991; 35: 294.

15. López, F., Martínez-Lage, J.F., Herrera, A., SánchezSolís, M., Torres, P., Palacios, M.I., Poza, M.: Penetrating craniocerebral injury from an underwater fishing harpoon. Childs Nerv Syst 2000; 16: 117-119.

16. Mouzopoulos, G., Tzurbakis, M.: Unusual cervical spine injury by fishing harpoon. Eur J Emerg Med 2009; 16: 209-211.

17. Nathoo, N., Nadvi, S.S.: Traumatic intracraneal anerysms following penetrating stab rounds to the head: two inusual cases and review of the literature. Cent Afr J Med 1999; 45: 213-217.

18. Salas Rubio, J.H.: Heridas craneoencefalográficas en la guerra. En: Salas Rubio JH. Fundamentos de Neurocirugía de Guerra. Ciudad de La Habana. Editorial Científico-técnica 1983; 16: 46.

19. Salvino, C.K., Origitano, T.C., Dries, D.J., Shea, J.F., Springhorn, M., Miller, C.J.: Transoral crossbow injury to the cervical spine: an unusual case of penetrating cervical spine injury. Neurosurgery 1991; 28: 904-907.

20. Smrkolj, V., Balazic, J., Princic, J.: Intracranial injuries by a screwdriver. Forensic Sci Int 1995; 29: 76: 211-216.

21. Taylor, A.G., Peter, J.C.: Patients with retained transcranial knife blades: a high-risk group. J Neurosurg 1997; 87: 512-515.

22. Temkin, N.R., Dikmen, S.S., Winn, H.R.: Management of head injury: Postraumatic seizures. Neurosurg. Clin. North Am 1991; 2: 425.

23. Tournier Lasserve, C.H.: Traiment des placers cranioencephaliques de guerre. Medicine et Armees 1983; 11:435.

Abarca-Olivas, J.; Concepción-Aramendía. L.A.; BañoRuiz, E.; Caminero-Canas, M.A.; Navarro-Moncho, J.A.; Botella-Asunción, C.: Perforating brain injury from a speargun. A case report. Neurocirugía 2011; 22: 271-275.

Correspondencia: Hospital General Universitario de Alicante. Servicio de Neurocirugía. Pintor Baeza s/n. 03010 Alicante. 